\title{
Kernos
}

Revue internationale et pluridisciplinaire de religion grecque antique

$34 \mid 2021$

Varia

\section{Purifier, soigner ou guérir? Maladies et lieux religieux de la Méditerranée antique à la Normandie médiévale}

\section{Elie Piette}

\section{Q OpenEdition}

1 Journals

\section{Édition électronique}

URL : https://journals.openedition.org/kernos/4033

DOI : $10.4000 /$ kernos.4033

ISSN : 2034-7871

\section{Éditeur}

Centre international d'étude de la religion grecque antique

\section{Édition imprimée}

Date de publication : 31 décembre 2021

Pagination : $315-316$

ISBN : 978-2-87562-305-8

ISSN : 0776-3824

\section{Référence électronique}

Elie Piette, «Purifier, soigner ou guérir ? Maladies et lieux religieux de la Méditerranée antique à la Normandie médiévale », Kernos [En ligne], 34 | 2021, mis en ligne le 31 décembre 2021, consulté le 15 mars 2023. URL : http://journals.openedition.org/kernos/4033 ; DOI : https://doi.org/10.4000/kernos. 4033

Ce document a été généré automatiquement le 15 mars 2023.

Tous droits réservés 


\title{
Purifier, soigner ou guérir? Maladies et lieux religieux de la Méditerranée antique à la Normandie médiévale
}

\author{
Elie Piette
}

\section{RÉFÉRENCE}

Cécile CHAPELAIN DE SEREVILLE et al. (dir.), Purifier, soigner ou guérir ? Maladies et lieux religieux de la Méditerranée antique à la Normandie médiévale, Rennes, Presses Universitaires de Rennes, 2020. 1 vol. 21,8 × $28 \mathrm{~cm}, 310$ p. (Archéologie \& Culture). ISBN : 978-2-7535-8025-1.

1 Issu d'un colloque tenu à Cerisy-la-Salle en octobre 2014, le présent ouvrage envisage les connexions entre médical et religieux au sein d'espaces dédiés à la guérison. Le matériau rassemblé, quoique varié tant d'un point de vue géographique (du monde grec jusqu'en Normandie) que temporel (de l'Antiquité au $\mathrm{xx}^{\mathrm{e}}$ siècle), concerne essentiellement le monde chrétien. Nous signalons toutefois quelques contributions dédiées aux sanctuaires guérisseurs grecs ainsi qu'aux pratiques religieuses et magiques antiques.

La figure du lézard sur une série de gemmes «magiques » d'époque romaine est pour Thomas Galoppin l'occasion de réfléchir au fonctionnement de ces amulettes destinées à soigner les affections ophtalmiques : par le biais d'une transcription graphique du rituel, la puissance guérisseuse de l'animal est transférée à l'artéfact. Les pratiques iatromagiques sont également approfondies par Magali de Haro Sanchez, qui souligne la complémentarité des médecines rationnelle, religieuse et magique dans les papyrus et les traités médicaux. 
Deux contributions concernent la représentation d'Asclépios et ses sanctuaires. Émilie Piguet déconstruit l'interprétation répandue d'Asclépios comme "dieu-médecin", héritée du positivisme scientifique du $\mathrm{XIX}^{\mathrm{e}}$ siècle: contrairement aux pratiques chirurgicales, c'est la puissance (dynamis) du dieu qui demeure à l'origine de la guérison, tandis que le pharmakon n'est qu'une manifestation, un prolongement de cette puissance. L'ajout d'une pharmacopée s'explique par une volonté de réalisme médical, les récits de guérison devenant les instruments d'un faire-croire en la science du dieu. En mettant en évidence, au sein de ces mêmes récits de guérison, les mentions récurrentes de la supplication et du déplacement vers le sanctuaire d'Épidaure, le regretté Pierre Sineux souligne le caractère physique de la démarche du consultant, tout en rejetant le concept inapproprié de "pèlerinage " : rejoindre un lieu sacré est le premier geste à accomplir afin d'entrer en contact avec la divinité et de bénéficier de son intervention.

4 Parmi les contributions relatives à l'Antiquité figurent encore la recherche d'Évelyne Samama sur la pratique de la sudation dans les installations thermales et dans le corpus hippocratique ainsi que l'étude de Christine Delaplace sur les mutations survenant dans les lieux de guérison en Gaule aux $\mathrm{IV}^{\mathrm{e}}-\mathrm{VI}^{\mathrm{e}}$ siècles de notre ère. Les différentes interventions témoignent de la difficulté, voire de l'impossibilité d'établir des frontières strictes entre pratiques médicales rationnelles, religieuses et magiques qui, loin de s'opposer, se combinent régulièrement. Plus largement, l'ensemble invite à réfléchir aux comportements religieux en matière de santé ainsi qu'aux pratiques purificatrices et magiques qui les accompagnent. Les actes de cette rencontre pluridisciplinaire s'adressent par conséquent non seulement à l'historien de la médecine, mais aussi à quiconque s'intéresse à l'histoire des mentalités.

\section{AUTEURS}

\section{ELIE PIETTE}

Université de Liège 